\title{
Os textos de divulgação científica em livros didáticos de Química e suas propostas metodológicas
}

\author{
Beatriz Tilschneider Garcia Rosa ${ }^{1}$, Marcia Borin da Cunha ${ }^{2}$ \\ ${ }^{1}$ Licenciada em Química pela Universidade Estadual do Oeste do Paraná (Unioeste/Brasil). \\ ${ }^{2}$ Doutora em Educação pela Universidade de São Paulo. \\ Professora da Universidade Estadual do Oeste do Paraná (Unioeste/Brasil).
}

The popular science texts in Chemistry textbooks and their methodological proposals

Informações do Artigo

Recebido: $11 / 12 / 2019$

Aceito: $19 / 12 / 2020$

Palavras chave: guia do Livro didático; mídia; ensino de Química.

Key words: textbook guide; media; Chemistry teaching.

E-mail:

beatriz.tilschneider@hotmail.com

\section{A B S T R A C T}

Popular Science an essential in the dissemination of science through science dissemination magazines, newspapers, the Internet, among others. The authors of Chemistry Textbooks (CTs) have appropriated popular science's texts to complement their work, bringing subjects with contemporary themes. We investigated the methodological position of SDTs found in CTs approved by the Programa Nacional do Livro Didático (Brasil, PNLD 2018). We searched all the complementary texts in the CTs and characterized them as SDTs according to the criteria of Zamboni (2001). The teaching methodologies where the science dissemination texts are: Problematization, Case Study, Research, Contextualization and Text Study. In this study we point out the main aspects of the use of these texts in textbooks and consequently in the classroom.

\section{INTRODUÇÃO}

A Divulgação Científica (DC), apesar da existência de pesquisas na área de Educação e Ensino de Ciências, ainda é um campo amplo, em constante construção, principalmente com as novas possibilidades de compartilhamento de informações que as mídias eletrônicas oferecem.

Utilizar a DC em uma metodologia de ensino e aproveitar seu máximo potencial em uma atividade pode ser um desafio, pois este tipo de recurso didático, assim como o estudo do texto, necessita de um bom planejamento (AZAMBUJA; SOUZA, 2011).

Um dos materiais didáticos que dão suporte ao trabalho do professor é o Livro Didático (LD). Após muitas discussões sobre o papel do LD, tornou-se fundamental o estudo e avaliação deste material, pois é a partir dele que o professor orienta suas atividades 

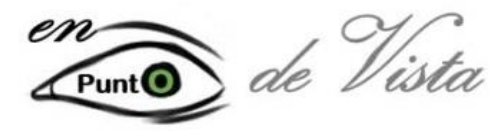

didáticas. O Programa Nacional do Livro Didático (PNLD), do governo federal brasileiro, determina condicionantes para que livros sejam distribuídos à rede pública de ensino, com finalidade de atingir os objetivos propostos nos documentos oficiais, sendo um deles, apresentar a Ciência e a Tecnologia que se encontra presente na sociedade contemporânea. Neste contexto, a DC é um meio de aproximar os estudantes do que é produzido nos campos da Ciência e Tecnologia. Para a disciplina de Química, os LDs trazem textos complementares sendo, alguns deles, Textos de Divulgação Científica (TDCs).

Apontamos que na seleção dos Livros Didáticos de Química (LDQs), promovida pelas instâncias responsáveis, dentre as normas estabelecidas para compor o material didático, não há um critério específico para a avaliação dos TDCs presentes nos livros, nem tão pouco uma análise da função didática destes textos, quando eles são inseridos nos diferentes capítulos do livro. No entanto, é preciso considerar que os TDCs operam em uma esfera da comunicação diferente da esfera didática e, portanto, constituem-se em gêneros diferentes. Desta forma, é importante questionar: como os TDCs são inseridos nos livros didáticos e qual sua função?

Posto isso, queremos entender quais as metodologias propostas por cada autor para inserção de TDCs em LDQs selecionados pelo último PNLD 2018, sugeridos no Guia do Livro Didático (GLD), no ano de 2017. Procuramos responder, a partir desta pesquisa, as seguintes questões: Qual a posição dos TDCs nos capítulos dos livros? Durante o desenvolvimento dos conteúdos como os TDCs estão relacionados ao conteúdo exposto no capítulo?

Tendo em vista os resultados da investigação de Cunha (2009), a qual indica que "[...] existe uma necessidade real de uma leitura crítica da divulgação científica por parte dos estudantes e esta leitura pode e deve ser realizada por meio de interações com textos de divulgação científica nas aulas de Ciências" (CUNHA, 2009, p. 06), entendemos que os TDCs inseridos nos LDQs são de fato importantes para estabelecer a relação de leitura e a criticidade do estudante enquanto cidadão em formação.

Neste artigo, trazemos uma análise crítica da posição metodológica dos TDCs em livros didáticos de química, pois um autor ao inserir um TDC deve reconhecer que um texto proveniente da mídia sofre "recontextualização" quando ele passa fazer parte de um material didático.

Ao analisar a posição metodológica dos TDCs, ao longo dos capítulos de LDQs e identificar ou aproximar quais são as metodologias propostas pelos autores/editores para utilização dos TDCs e as associações com os temas propostos, pretendeu-se ter uma compreensão das propostas metodológicas para o uso dos TDCs. Desta forma foi possível evidenciar quais as vantagens e desvantagens de cada proposta.

\section{O Livro Didático}


O Livro didático possui uma extensa trajetória até chegar aos modelos atuais, passando por diversas adaptações, por exemplo, a forma de apresentação visual dos livros e a mudança das tendências pedagógicas, dentre elas, o construtivismo.

Quando a educação era um privilégio de poucos, este recurso era constituído de uma simples cartilha. Contudo, com a crescente preocupação de alfabetizar a população, passouse a empreender novos recursos para o ensino e livro torna-se coletivo (CHOPPIN, 2014).

Assim, começou-se a refletir sobre as funções deste material, e se anteriormente, não era um objeto de estudo que chamasse a atenção de pesquisadores, agora passa a ser um desígnio de muitas pesquisas. Isto se deve às diversas funções que podem ser atribuídas ao LD, que dependem do ambiente sociocultural, da época, das disciplinas, dos níveis de ensino, dos métodos e as formas de utilização (CHOPPIN, 2014),

[...] é preciso levar em conta a multiplicidade dos agentes envolvidos em cada uma das etapas que marca a vida de um livro escolar, desde sua concepção pelo autor até seu descarte pelo professor e, idealmente, sua conservação para as futuras gerações (CHOPPIN, 2014, p. 553-554).

Portanto, o LD passou e passa frequentemente por adequações, que são embasados cada vez mais em novas metodologias de ensino, com o intuito de "fugir" do ensino tradicional, muito criticado nos meios acadêmicos. Com o surgimento de um programa nacional para o livro didático, este recurso tornou-se o elemento mais importante de apoio ao trabalho do professor, tendo como principal função a instrumental, pois é uma ferramenta para o ensino das diferentes disciplinas escolares.

No Brasil existem as políticas públicas que visam orientar autores de livros para sua estruturação. No caso do LD existe o Programa Nacional do Livro Didático (PNLD) que visou corrigir alguns processos muito criticados no que diz respeito à natureza do livro didático, tais como: a importância de indicação do livro didático pelos professores; reutilização do livro, a abolição do livro descartável e o aperfeiçoamento das especificações técnicas para sua produção (CARVALHO, 2017).

Nos anos de 1993 e 1994, foram criados critérios de avaliação dos livros didáticos em um documento intitulado "Definição de Critérios para Avaliação dos Livros Didáticos". No ano de 1996, iniciou-se o processo de avaliação pedagógica dos livros inscritos no PNLD, no qual o produto é o "Guia de Livros Didáticos (GLD)" (CAVALHO, 2017).

O GLD apresenta o resultado do processo de avaliação das obras submetidas aos editais, que tem por objetivo a aquisição pelo Governo Federal de LDs destinados aos estudantes e professores do Ensino Médio das escolas públicas brasileiras. O GLD de Química, do PNLD 2018, resulta do trabalho realizado por uma equipe de especialistas em ensino de Química, professores que atuam em instituições de Ensino Superior ou na 

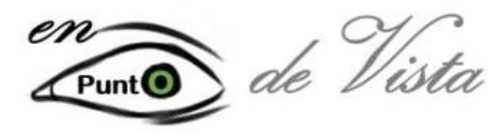

Educação Básica. Esta análise considera a trajetória do ensino de Química nas escolas públicas, assim como avanços nos estudos acadêmicos que visam o melhoramento do Ensino de Química.

Contudo, dentre os critérios de avaliação dos LDQs, não há um item para discutir a presença de DC nestes materiais. Há apenas orientações sobre o cotidiano e o contexto que devem ser associados com os conhecimentos químicos para auxiliar a superação de teorias desconexas para os estudantes. Neste contexto é importante um debate sobre a divulgação científica na escola, em especial em materiais didáticos, como é o caso dos LDs. Sobre isso trazemos algumas definições no próximo item.

\section{A Divulgação Científica no Contexto Escolar}

A Divulgação Científica (DC) possui origem na difusão científica e trata-se de todo esforço para a comunicação da informação científica e tecnológica para todo público, sejam especialistas ou público leigo. A difusão científica, que têm por objetivo informar especialistas é chamada de disseminação científica e a difusão destinada ao público em geral (não especialista) é denominada Divulgação Científica (CUNHA, 2019). Os termos vulgarização e popularização da ciência, também são aceitos, porém no Brasil, o termo DC é mais recorrente. Assim como para Zamboni (2001), a divulgação científica, é entendida, como uma atividade de difusão, dirigida para fora de seu contexto originário, de conhecimentos científicos produzidos e circulantes no interior de uma comunidade de limites restritos, ao público em geral (ZAMBONI, 2001).

Há diversos meios de veiculação para a DC, como os jornais, as revistas, os museus, os programas de rádio e televisivos, a internet, entre outras, como convenções de ciência abertas ao público, livros de divulgação científica, exposições de ciências. Zamboni (2001) inclui também os livros didáticos, as aulas de ciências do Ensino Médio, os cursos de extensão para não especialistas, as histórias em quadrinhos, os suplementos infantis, documentários, etc. (ZAMBONI, 2001).

Mas para um assunto de ciência ser divulgado, o discurso científico sofre uma reelaboração discursiva, adequando a sua linguagem aos parâmetros nos quais o público leigo possa compreender a informação. Zamboni (2001) assume que a prática da divulgação científica constitui uma atividade de reformulação discursiva. Em sua análise a autora caracteriza as "[...] ocorrências do discurso de DC, como resultado de suas condições de produção, é a superposição de traços de cientificidade, laicidade e didaticidade, que se deixam mostrar, em graus variados, na superfície dos textos" (ZAMBONI, 2001, p. 129).

$\mathrm{E}$, além dos problemas do próprio discurso, em alguns momentos, nesta transição podem ocorrer erros conceituais, dados mal interpretados que podem levar a conclusões 

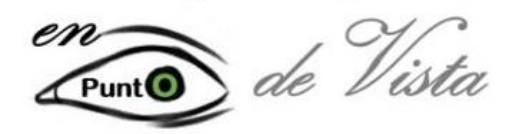

Chemical Education in Point of View

2527-0915

errôneas, devido à natureza crítica que o divulgador tem em relação à produção científica e tecnológica. Mas, o que acontece quando um texto de divulgação científica (TDC) passa a fazer parte de um livro didático? Neste estudo consideramos que há um processo de recontextualização, pois o texto sai da esfera midiática e passa a fazer parte da esfera pedagógica, ou seja, passa de um contexto para o outro. Isso tem acontecido nos livros mais recentes destinados ao ensino de Química, pois autores de LDs, na tentativa de incrementar suas obras e motivar os estudantes ao estudo, incluem, em suas obras, TDCs presentes na mídia. Este movimento é uma tentativa de aproximar os conteúdos da Química do contexto social. Entretanto, há que se considerar que esse processo demanda atenção, destacando-se o modo como TDC será utilizado em sala de aula, pois um texto da mídia ao ser inserido no livro sofre mudanças no que se refere aos objetivos e público endereçado. Torna-se então um texto com outra finalidade, a de ensinar, possuindo, portanto, um público específico, os estudantes. Assim, o TDC é inserido em outra esfera, a escolar, com finalidade didática, mudando, desta maneira, o contexto de emprego deste texto.

Lima e Giordan (2015) refletem sobre o grande interesse da comunidade de pesquisadores de entender a divulgação da ciência, e como ela, por fim, acaba sendo utilizada na sala de aula, assim afirmam que:

Essa temática [investigações da DC] é destaque na pesquisa de ensino de ciências por meio de investigações que contemplam espaços típicos de educação não formal [...] e pesquisas que investigam situações de ensino que estão numa interface em espaços formais de ensino utilizam como base de suas atividades materiais de educação não formal ou DC (LIMA; GIORDAN, 2015, p. 285).

Ainda nesta linha de pensamento, os autores acima citados, dizem que a utilização da DC em sala de aula tende "[...] a aproximar os elementos da ciência e da tecnologia aos recursos e linguagens [...] comuns à sociedade" (LIMA; GIORDAN, 2015, p. 286). Mas, e quando a DC já está introduzida nos LDs? Para estes autores, o estudante entra em contato com a DC pela mediação do professor, mas quando os TDCs já estão inseridos nos LDs essa mediação ocorre entre os autores dos LDs e os estudantes, no sentido de que este é um material didático assegurado (teoricamente) pelo estado. Assim, os estudantes são afortunadamente "donos" deste livro pelo período em que vão utilizar, tendo acesso livre a ele. Mesmo quando intuímos que isto raramente ocorre, o estudante pode fazer a leitura deste material em outros horários que não sejam durante as aulas de Química na escola.

Em todo caso, para este estudo, é preciso refletir sobre o papel da DC, no seu processo de ressignificação, assim como Marandino (2001) discute sobre o discurso museal: "O saber científico produzido, ao ganhar espaços sociais, sofre mudanças, as quais 

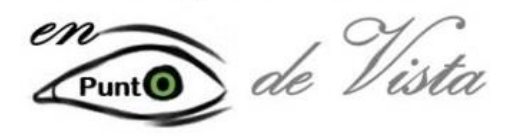

Chemical Education in Point of View

2527-0915

dependem também daqueles que interagem com ele, seja para divulgá-lo, seja para ensinálo, seja para compreendê-lo" (MARANDINO, 2001, p. 01).

De modo geral podemos dizer que os TDCs são veiculados por vários meios midiáticos, ou seja, revista, jornal, periódico ou, nos dias atuais, como material disponível na internet. Logo existem modalidades como web sites com objetivo de fazer a disseminação da ciência. As revistas de DC são direcionadas à diferentes padrões de conhecimento e públicos diversos. Elas são elaboradas para o público amplo e heterogêneo, sendo assim este gênero (a DC), está ao alcance de qualquer pessoa, onde faixas etárias, sociais, intelectuais e culturais são indefinidas. Para Marandino (2001) "[...] considera-se que os processos de transformação do conhecimento científico com fins de ensino e divulgação não constituem simples "adaptações" aos diferentes padrões de produção de conhecimento." (MARANDINO, 2001, p. 04).

Buscando compreender este processo de entrada de um TDC no LDQ optamos pela Teoria da Recontextualização, proposta por Bernstein (1996), pois, para a análise que aqui empreendemos, esta Teoria nos parece mais apropriada para o estudo dos TDCs nos LDs, sendo nosso foco compreender como ocorre a transferência dos textos em diferentes contextos de produção e reprodução, considerando também outros fatores, além da ressignificação de ideias, como as relações de poder e regulação do discurso que endossam o âmbito social.

$\mathrm{Na}$ recontextualização, para Bernstein (1996) o discurso pedagógico é o discurso construído a partir de outros discursos.

O discurso pedagógico é um princípio para apropriar outros discursos e colocá-los numa relação mútua especial, com vistas à sua transmissão e aquisição seletivas. O discurso pedagógico é, pois, um princípio que tira (desloca) um discurso de sua prática e contextos substantivos e relocar aquele discurso de acordo com seu princípio de localização de reordenamento seletivos (BERNSTEIN, 1996, p. 259).

Para Marandino (2001) na recontextualização o discurso pedagógico age “[...] de forma seletiva, apropriando, refocalizando e relacionando outros discursos a partir de sua própria ordem, tornando-os outro discurso" (MARANDINO, 2001, p. 103).

Cunha (2010) quando se refere à recontextualiação como estratégia discursiva define contexto como,

[...] conjunto de condições concretas que responde pela configuração particular que une autor e leitores, num amplo espectro de ideias, 

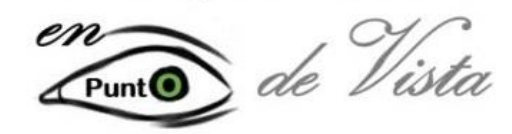

Chemical Education in Point of View

https://revistas.unila.edu.br/eqpv 2527-0915

experiências, expectativas e condutas envolvidas no cenário da produção material e cultural da sociedade (CUNHA, 2010, p. 30).

No contexto da DC há um objetivo delineado pela disseminação científica e no contexto escolar há um objetivo pedagógico. Assim, a informação é reescrita pelo interlocutor, de modo a atender a um novo espaço de divulgação, o da esfera didática.

No enfoque que pretendemos dar a DC, Motta-Roth (2010) descreve a mídia "[...] como um contexto recontextualizador que mediatiza/populariza a ciência para a sociedade" (MOTTA-ROTH, 2010, p. 162). Portanto, quando ocorre a recontextualização do TDC, ou seja, a passagem do texto da esfera midiática para a esfera educacional - mesmo que seja na íntegra -, o TDC passa a atender outras expectativas, experiências e novas construções de ideias, com objetivos diferentes, sofrendo uma recontextualização.

Entretanto, ao analisar os textos presentes em LDQs, nos deparamos com textos que não podem ser caracterizados como TCDs, pois são provenientes de contextos diferentes dos espaços que pretendem divulgar a ciência. Neste sentido, Zamboni (2001) nos aponta elementos que norteiam a caracterização de um TDC, considerando 12 critérios: 1 . Fonte de onde foi extraído; 2. Data da publicação; 3. Nome do jornalista; 4. Antitítulo; 5 . Título; 6. Intertítulo(s); 7. Resenha; 8. Lide; 9 . Fotos e/ou imagens; 10. Box; 11. Tema; 12. Nome do(s) especialista(s).

A partir do trabalho de Zamboni (2001) é possível classificar os TDCs, no entanto, percebemos que de todos os textos presentes nos LDQs, poucos deles atendem a todos esses quesitos, devido ao objetivo e o novo local de circulação.

\section{APORTES METODOLÓGICOS}

A pesquisa outorgada a este trabalho é de caráter bibliográfico, portanto a amostra utilizada foi constituída por dezoito volumes das seis coleções de Livros Didáticos de Química (LDQ), selecionadas pelo PNLD 2018, sendo que cada uma das coleções possui três volumes.

Para sistematizar a análise, cada coleção foi codificada com uma letra ( $A, B, C, D, E, F)$ e cada volume foi representado por números $(1,2,3)$. No Quadro 1 apresentamos o título da obra, autor e codificação das coleções analisadas.

Quadro 1. Denominação da amostra.

\begin{tabular}{|c|c|c|}
\hline Título da obra & Autores & $\begin{array}{c}\text { Código de análise } \\
\text { por volume }\end{array}$ \\
\hline Química & $\begin{array}{c}\text { Carlos Alberto Ciscato, Luis } \\
\text { Fernando Pereira, Emiliano } \\
\text { Chemello e Patrícia Proti }\end{array}$ & A1, A2, A3 \\
\hline & Cheme & \\
\hline
\end{tabular}




\section{Educação Química}

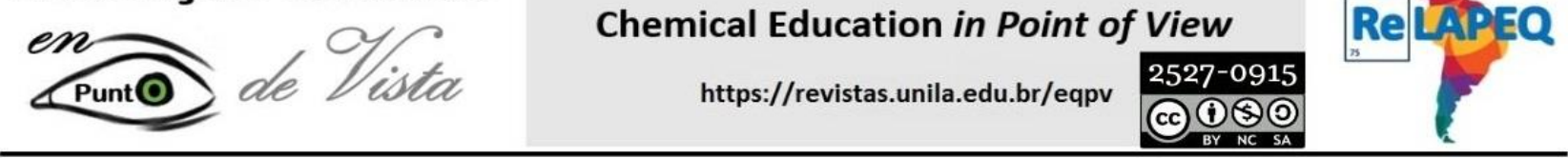

\begin{tabular}{|c|c|c|}
\hline Química: ensino médio & $\begin{array}{c}\text { Eduardo Fleury Mortimer e } \\
\text { Andrea Horta Machado }\end{array}$ & B1, B2, B3 \\
\hline Química: ensino médio & Martha Reis & C1, C2, C3 \\
\hline Coleção Ser Protagonista & $\begin{array}{c}\text { Julio Cezar Foschini Lisboa - Obra } \\
\text { coletiva }\end{array}$ & D1, D2, D3 \\
\hline Vivá: Química: Ensino Médio & $\begin{array}{c}\text { Vera Lúcia Duarte de Novais e } \\
\text { Murilo Tissoni Antunes }\end{array}$ & E1, E2, E3 \\
\hline Química Cidadã & $\begin{array}{c}\text { Wildson Santos e Gerson Mól } \\
\text { (coordenadores) }\end{array}$ & F1, F2, F3 \\
\hline
\end{tabular}

Fonte: as autoras.

Diante da seleção de livros didáticos realizamos a pesquisa em três etapas:

1 - Levantamento geral em relação à quantidade de textos complementares encontrados em cada um dos dezoito volumes da amostra. Os dados foram organizados em uma planilha Excel ${ }^{\circledR}$ com informações do texto como: título dos TDCs, página do texto no LDQ, local da fonte original do texto da internet, autores do texto original, indicados pelo autor do livro e data de acesso feito pelo autor do livro. Para selecionar os TDCs presentes nos livros, utilizamos seis dos doze critérios propostos por Zamboni (2001). Neste direcionamento são considerados os itens 1, 2, 3, 5, 9 e 10 dos doze supracitados, uma vez que nem todos os TDCs presentes nos LDs atendem à todos os critérios, devido à adaptação ao corpo do contexto didático.

2 - Consultamos todas as referências indicadas e descartamos os textos que não foram encontradas nas referências fornecidas pelos autores, seja por indisponibilidade de acesso à fonte original, seja por erro na informação do autor. Descartamos também textos que não atenderam aos critérios de classificação de TDC propostas por Zamboni (2001).

3 - A partir dos TDCs selecionados, efetuamos a análise da posição metodológica destes textos nos capítulos dos LDQs. Realizamos uma leitura flutuante de cada capítulo para identificar o conteúdo que estava sendo abordado. Posteriormente, uma leitura reflexiva dos textos, a fim de entender qual a proposta do autor para a utilização deste recurso e qual a relação possível a ser estabelecida entre os conteúdos e conceitos trabalhados naquele capítulo com os TDCs, observando também, a posição deles no capítulo que nos pudesse indicar a finalidade deste texto ali alocado.

De modo inicial foi possível classificar os livros em propostas tradicionais e inovadoras, considerando sempre a posição metodológica dos TDCs no interior dos capítulos. Para a apresentação das análises o faremos na forma de construção textual, apontando os elementos observados durante a leitura dos capítulos e a relação dos TDCs 


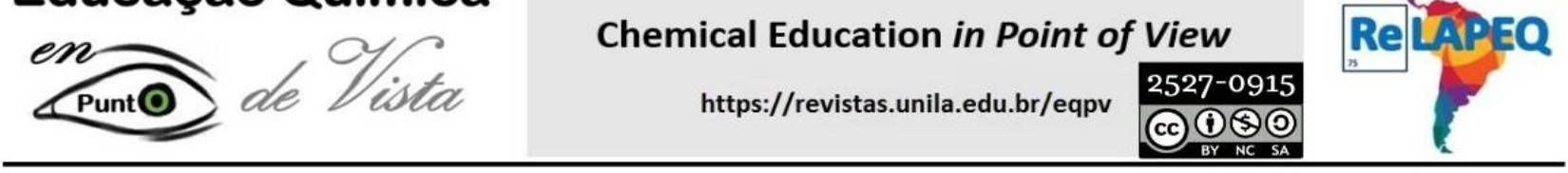

com propostas metodológicas, como: Problematização, Estudos de Caso, CTS, Ensino por Investigação, dentre outras. Nesta construção textual, sempre que possível, trazemos exemplos de TDCs presentes nos livros, como forma de exemplificação, assim como a apresentação de aporte teórico que possa dar sustentação às nossas análises.

\section{RESULTADOS E DISCUSSÕES}

\section{O Texto de Divulgação Científica no livro didático}

De modo geral, no livro didático, o TDC apresenta-se das seguintes formas: citação, sugestão ou recomendação de leitura, recorte de pequeno trecho do texto original, texto adaptado ou editado e a presença do texto na íntegra (MARTINS; DAMACENO, 2002). Evidentemente que, em sala de aula, o objeto de ensino não será o TDC, e sim, o texto didático, legitimado pelo saber científico.

Ao analisar os TDCs nos LDQs, foi possível observar as concepções da natureza destes materiais didáticos. Em outras palavras, identificar quais as intenções didáticas que estas obras apresentam, visto que na análise foi possível perceber nitidamente o que Mól (2012) pontua:

Existem dois tipos de LD, que são diferenciados por suas concepções. Os primeiros são produzidos por um autor, ou pequeno grupo de autores, atendendo ou se encaixando em demandas de editoras. $O$ segundo grupo de livros é caracterizado pelo resultado de trabalhos de pesquisa e pela incorporação de avanços e estudos da área de Ensino de Ciências, e especificamente, de Química (MÓL, 2012, p. 30).

Isto é evidenciado em nossa pesquisa, uma vez que a proposta de ensino é correlacionada com o uso de recursos como, por exemplo, os TDCs, nos quais, em alguns casos, os autores têm se empenhado em fazer uso das novas tendências educacionais para o Ensino de Química, buscando o aperfeiçoamento de sua obra, além de adequar-se aos critérios estabelecidos pelo PNLD. Desta forma, inserem-se TDCs como propostas alternativas, do mesmo modo como Maldaner e Zanon (2004) esclarecem:

Pela influência de propostas alternativas, e mais recentemente, das orientações dos PCNs (Parâmetros Curriculares Nacionais), livros didáticos tradicionais passaram a inserir temas sociais, preocupações com 0 contexto, temas transversais, temas da atualidade e do sistema produtivo sem abrir mão das sequências lineares de conteúdos [...] (MALDANER; ZANON, 2004, p. 112-113). 
Já os LDs do segundo grupo, classificados por Mól (2012), caracterizados como inovadores, são aqueles que pouco chamam a atenção dos professores no momento da escolha do material didático, pois

[...] pretendem incluir avanços decorrentes de estudos da área de Ensino de Química/Ciências e veiculam propostas pedagógicas com visões curriculares inovadoras, diferenciando-se das propostas convencionais centradas num modelo de ensino que privilegia a memorização em detrimento da compreensão conceitual (MÓL, 2012, p. 30-31).

É muito comum ouvir de professores mais antigos sobre a escolha do material didático, nos quais alguns julgam os livros mais contextualizados e com propostas inovadoras "muito difíceis de trabalhar". Obras conservadoras preservam "certa linearidade" dos conceitos, sem grandes desafios e mudanças para os professores. Portanto, para os professores que defendem estes materiais, há a ideia de ser mais simples de trabalhar, pois já conhecem "a receita". Como Santos e Maldaner (2010) apontam o que ocorre é "[...] que prevalecem certos hábitos que foram se consolidando ao longo dos anos e que precisarão de outros esforços para serem superados" (SANTOS; MALDANER, 2010, p. 275).

Além destes, existem outros fatores que influenciam nessa adoção de obras com cunho mais conservador, ou seja, a pressão sobre o professor em relação ao seu trabalho, um currículo extenso a ser cumprido em um curto período de tempo, a estrutura escolar e a falta de recursos, por exemplo.

\section{Textos de Divulgação Científica e a metodologia do Livro Didático}

O foco desta análise foi compreender a posição metodológica dos TDCs nos LDs, mais especificamente as propostas dos autores frente ao TDC. Para tanto, trazemos uma breve caracterização das obras analisadas.

De acordo com as impressões dos próprios autores e informações presentes no Guia do Livro Didático (Brasil, 2017), encontramos as seguintes considerações:

Livro A - Os capítulos estão organizados com textos e imagens iniciais de apresentação e introdução aos assuntos que serão abordados, seguidos de questões e de reflexões para o levantamento dos conhecimentos prévios dos estudantes. A obra articula os códigos da Química com os campos teórico e fenomenológico. Contempla os aspectos teórico-conceituais da Química em relação à História da Ciência e a experimentação;

Livro B - Se contrapõe ao ensino excessivamente conceitual, cuja inter-relação é dificilmente percebida durante as aulas de Química. Ao romper com o ensino de conteúdos 

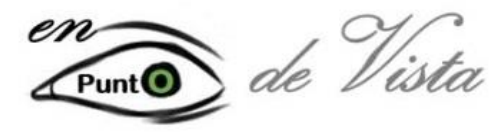

por meio da memorização, traz propostas de atividades investigativas, contextualização e abordagens temáticas com proposição de uma aprendizagem ativa. Os conteúdos fundamentais da Química são apresentados e desenvolvidos de forma não convencional, com foco na investigação, na interdisciplinaridade e na problematização, de modo que o conceito seja inserido gradualmente e de forma contextualizada;

Livro C - Na abertura das unidades, a coleção traz uma contextualização do tema principal e, em seguida, para iniciar os capítulos, apresenta a seção "Foi notícia!", que trata de algum fato, veiculado pela mídia, com o objetivo de auxiliar na problematização do tema do capítulo. Antes de fechar o capítulo, a notícia é retomada, buscando responder às questões levantadas inicialmente. Por fim, podem ser aproveitados os textos das seções "Foi notícia!", Retomando a notícia e Compreendendo o mundo, principalmente para problematizar as aulas com aspectos socioambientais, bem como para trabalhar as habilidades de leitura e interpretação de textos;

Livro D - Nesta obra, as relações entre o conhecimento químico e situações cotidianas são apresentadas na abertura das unidades e dos capítulos. Em seções especiais como Ciência, Tecnologia e Sociedade e Química tem história são apresentados textos atuais e de circulação social, enfatizando a relevância do conteúdo abordado, incentivando a discussão do assunto em uma visão crítica. Todos os boxs e seções da obra são fundamentados em um dos quatro pilares: contextualização e interdisciplinaridade; compromisso; visão crítica; iniciativa. A obra opta por apresentar a sequência dos conteúdos químicos de maneira convencional;

Livro E - O conhecimento químico é conduzido, ao longo da obra, de forma contextualizada, considerando as dimensões sociais, econômicas e culturais da vida humana, não se restringindo à menção de exemplos ilustrativos. Essa abordagem contribui para a superação da crença de que a Química é permanentemente responsável por catástrofes ambientais, processos de poluição e pela artificialidade de produtos, principalmente aqueles relacionados com alimentação e com medicamentos. A obra possibilita trabalhar com o conhecimento científico a partir de uma linguagem constituída por representações e símbolos especificamente significativos para a Química e com sua mediação didática. Os volumes permitem que os estudantes se envolvam em atividades de leitura e de compreensão das representações nas suas diferentes formas;

Livro F - A obra busca promover o desenvolvimento cognitivo dos estudantes a partir de questionamentos e de atividades que exigem reflexão e elaboração de novos conceitos. Possui potencial pedagógico que considera a formação para a cidadania e para o desenvolvimento do protagonismo do estudante. Contribui para o desenvolvimento de habilidades cognitivas dos estudantes, por meio de situações - problema (BRASIL, 2017). 

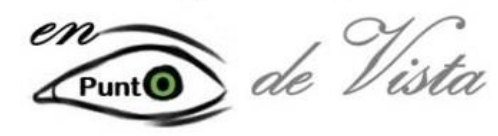

Chemical Education in Point of View

2527-0915

https://revistas.unila.edu.br/eqpv

A partir das considerações feitas pelo Guia do Livro Didático classificamos os LDQs em duas abordagens metodológicas (a partir das propostas para os TDCs): tradicional e inovadora. As obras ditas tradicionais são os " $A$ ", " $D$ " e " $E$ ". Curiosamente, nos dois últimos editais do PNLD são essas coleções as mais adotadas pelos professores da rede pública do núcleo regional de educação onde esta pesquisa foi realizada, o que corrobora com as posições feitas anteriormente sobre a postura dos professores, isto é, as coleções que tratam dos conteúdos químicos de forma sistemática, com abordagens conceituais conservadoras ainda são a opção de muitos professores.

Os LDQs chamados inovadores são produtos de pesquisas na área da Educação/Ensino de Ciências. Estes são os livros "B", "C" e "F". Estas obras buscam relacionar os conteúdos químicos com o cotidiano, contextualizando e fazendo relações importantes com a História da Ciência, Experimentação Investigativa, Abordagens Temáticas e Problematização, por meio da inserção dos TDCs.

A partir da busca por TDCs, nos três volumes de cada uma das seis coleções, encontramos um total de 134 TDCs, com uma diferença significativa entre as coleções, assim como apresentamos no Quadro 2. Houveram, também, diferenças entre os volumes das próprias coleções, isto é, em uma mesma coleção o volume 2 e 3 apresentou quantidades significativas de TDC, já no volume 1 , encontramos um número reduzido de TDCs. Entretanto, como a nossa análise é referente à metodologia de utilização destes TDCs ao longo do capítulo e, desta forma, a metodologia se repete entre os volumes. O quadro abaixo traz um panorama geral sobre o que se pode encontrar nos livros de química a respeito de TDCs.

Quadro 2: Amostragem quantitativa para análise.

\begin{tabular}{|c|c|c|}
\hline $\begin{array}{c}\text { Código de análise } \\
\text { (por volume) }\end{array}$ & $\begin{array}{c}\text { Textos } \\
\text { encontrados nos } \\
\text { LDQs }\end{array}$ & $\begin{array}{c}\text { Textos encontrados pelo } \\
\text { título ou endereço } \\
\text { eletrônico na internet }\end{array}$ \\
\hline A1, A2, A3 & 39 & 8 \\
\hline B1, B2, B3 & 24 & 13 \\
\hline C1, C2, C3 & 49 & 27 \\
\hline D1, D2, D3 & 135 & 56 \\
\hline E1, E2, E3 & 120 & 28 \\
\hline F1, F2, F3 & 3 & 2 \\
\hline
\end{tabular}




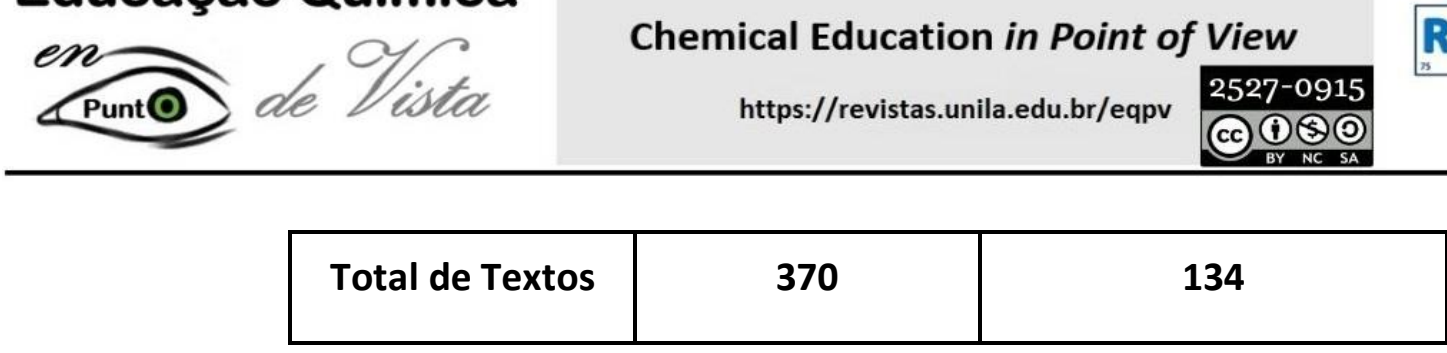

Fonte: as autoras.

A quantidade de textos encontrados a partir de seus links, títulos e autores são em quantidade reduzida em relação aos textos inseridos pelos autores dos LDs. Salientamos que todo texto complementar e, em especial, os TDCs são provenientes da esfera midiática e, portanto, devem estar devidamente referenciados a partir da sua fonte primária, por exemplo, a maioria dos TDCs é do portal G1 (globo.com), Folha de São Paulo (uol.com.br), Ciência Hoje, Jornal Estado de Minas, Exame e Estadão, entre outros. Temos ainda textos das revistas: Superinteressante, Galileu, Inovação Tecnológica e Comciência, e alguns blogs como, por exemplo, o blog do Dr. Dráuzio Varella.

Salientamos que, em alguns casos, os textos nos livros aparecem com falta de referência ou referência inadequada, o que o torna passível de dúvida em relação a sua autoria ou alterações que podem ter sido realizadas para a transposição do texto para o livro didático. Precisamos deixar claro que, um conteúdo disponível na internet não é algo estável, podendo existir ou não em um determinado período de consulta. No caso desta pesquisa, as consultas foram realizadas entre março e dezembro de 2018. Além disso, temos que considerar que as obras analisadas foram elaboradas no ano de 2016.

Constatamos também uma diferença quantitativa entre os volumes, alguns assuntos e formas de trabalho do autor propuseram uma oscilação de TDCs, em termos de quantidade. Isto pode ocorrer devido ao tipo de proposta que o conteúdo químico ou a forma com que o autor trabalha este tema, ou seja, depende da abordagem e das possibilidades que o conceito proporciona.

Evidenciamos que no PNLD 2018 existem duas novas coleções: a dos autores Ciscato, Pereira, Chemello e Proti (coleção A) e Novais - Obra Coletiva (coleção E). Em relação às coleções "veteranas" (B, C, D e F) fizemos um comparativo com os resultados quantitativos entre os TDCs que cada autor utiliza. Nesse sentido percebemos que os autores não apresentaram diferença significativa quanto ao uso de TDCs de uma edição para a outra, pois, a proposta da obra, seja problematizadora, investigativa ou tradicional, permanece a mesma.

As coleções ' $D$ ' e 'E', em comparação com as demais, possuem maior quantidade de TDCS. Entretanto, apesar de utilizar o recurso, a coleção ' $D$ ', com maior quantidade de TDC, não possui uma metodologia ou abordagem que faz relação diretamente com o texto principal e o conteúdo de química. Os TDCs são apresentados em box ou na seção Ciência, Tecnologia e Sociedade, sempre no final do capítulo. Estas são características de LD dito tradicional, no qual os conteúdos são separados e sistematizados e, portanto, é muito mais fácil ignorar os TDCs do capítulo, pois não estão correlacionados ao texto didático principal. 


\section{A posição dos TDCs no capítulo e a metodologia}

No Quadro 3, buscamos relacionar a posição do TDC no capítulo por meio das propostas metodológicas que mais se aproximam para o uso dos TDCs em atividades didáticas.

Quadro 3: Aproximação metodológica dos TDCs em cada obra.

\begin{tabular}{|c|l|}
\hline Coleção & \multicolumn{1}{|c|}{ Aproximação metodológica para os TDCs } \\
\hline A & $\begin{array}{l}\text { Contextualização, porém, apresenta apenas elementos do cotidiano; o } \\
\text { TDC possui apenas uma função no capítulo. }\end{array}$ \\
\hline B & $\begin{array}{l}\text { Contextualização com propostas de atividades investigativas; o TDC } \\
\text { possui função de complementar a problematização do conteúdo e } \\
\text { apresentar elementos do cotidiano estabelecendo relações entre } \\
\text { conceitos químicos. }\end{array}$ \\
\hline C & $\begin{array}{l}\text { Problematização, com possíveis Estudos de Caso, porém apresenta os } \\
\text { conteúdos químicos de forma sistemática; a função do TDC é dar início } \\
\text { à problematização pretendida no capítulo. }\end{array}$ \\
\hline D & $\begin{array}{l}\text { Exemplificação: estimula a reflexão e posicionamento dos temas; o TDC } \\
\text { é uma ferramenta utilizada como reflexão sobre os assuntos } \\
\text { relacionados ao tema do capítulo. }\end{array}$ \\
\hline E & $\begin{array}{l}\text { Multipropostas/diversas propostas; em geral o texto antecede as } \\
\text { atividades/perguntas. }\end{array}$ \\
\hline F & \begin{tabular}{l} 
Problematização do conteúdo. \\
\hline
\end{tabular}
\end{tabular}

Fonte: as autoras.

O Livro A, possui uma estrutura capitular diferente das outras obras. Seus capítulos são subdivididos por Temas, por exemplo, no volume 1, capítulo 1: "A conservação dos alimentos e as transformações dos materiais", possui o Tema 1: "As transformações químicas e os alimentos". Desta forma, o autor utiliza os TDCs com enfoque multidisciplinar, para retomar os conceitos químicos estudados no tema, por meio de atividades. Os capítulos são longos e os conceitos são trabalhados dentro da temática do capítulo. Portanto, o TDC possui a função de envolver os conceitos químicos, a temática e a contextualização pretendida no capítulo, além de apresentar discussões sobre temas importantes para a sociedade, como é o caso dos alimentos. 

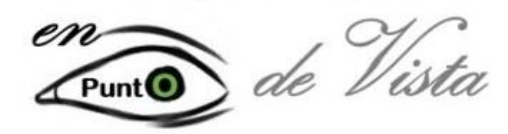

Chemical Education in Point of View

2527-0915

Esta obra possui TDCs como forma de mostrar as aplicações e possibilidades de encontrar dados dos conhecimentos químicos no cotidiano. Como exemplo, temos o texto 1 , do volume 1, do Livro A: "Suplementação de Cálcio" que está localizado na página 201, Capítulo - Quantidade de matéria e estequiometria: obtenção e principal aplicação do enxofre. O texto trata das quantidades essenciais de cálcio para o organismo, contraindicações e possíveis reações adversas. No final do texto há questões de aplicação direta dos conceitos. O objetivo do TDC é possibilitar que o estudante relacione o conhecimento químico com um determinado tema.

No entanto, do ponto de vista da classificação dos LDs, quanto a sua proposta metodológica para os TDCs, esta obra é classificada como tradicional, sua abordagem, caracterizada por pouca problematização dos conceitos e apenas aplicação de conhecimento para responder algumas perguntas. Aproxima-se de propostas tradicionais, com abordagem pouco reflexiva e que não prioriza o desenvolvimento de outras habilidades, como a oralidade por meio da discussão e argumentação sobre o assunto.

O livro B é classificado como proposta de material didático inovador. Os autores desta obra priorizaram o ensino por meio da contextualização dos conceitos químicos relacionando-os com o cotidiano. Os capítulos são longos, o conteúdo de química não é explícito como comumente os livros convencionais o trazem. É necessário emergir na leitura, para identificar de qual conteúdo químico o capítulo trabalha, e isto ocorre por via da destreza em colocar os conceitos químicos em contextos, como os sociais, ambientais, domésticos, econômicos, ou seja, assuntos rotineiros para os estudantes. Os TDCs são empregados de maneira a estabelecer relações diretas com o conteúdo químico. As questões de reflexão e interpretação do texto sugerem que os TDCs sirvam como informações adicionais para agregar ao contexto criado. Também são utilizados como introdução para atividades investigativas, podendo ser caracterizados como ponto inicial para a formulação da situação-problema, etapa primeira da metodologia por investigação.

O ensino por investigação consiste em desenvolver habilidades de produção de conhecimento a partir de experiências que os estudantes endossam ao longo da aprendizagem, assim como Capecchi (2014) pontua que:

[...] situações-problema podem ser apresentadas aos estudantes de diversas formas, desde problemas experimentais, com ações diretas dos estudantes sobre os materiais ou na forma de demonstrações investigativas, até problemas envolvendo outros recursos, como o trabalho com figuras ou textos (CAPECCHI, 2014, p.26).

Desta maneira, os autores do Livro B, fizeram uso do recurso de maneira a aproveitálo em diferentes situações, não sendo uma simples curiosidade ou sem função para aquele momento contextual. Citamos como exemplo o Texto: "Racionamento é inevitável e não 

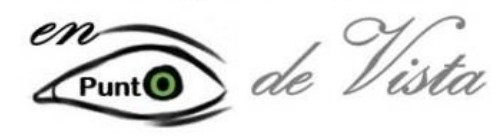

Chemical Education in Point of View

2527-0915

https://revistas.unila.edu.br/eqpv

tem prazo para acabar" localizada na página 185 do Capítulo "Água nos ambientes urbanos: Química para cuidar do planeta" que trata da qualidade da água relembrando conceitos de solubilidade de gases em líquidos, $\mathrm{pH}$ e outros parâmetros físico-químicos e biológicos como turbidez e os coliformes. A proposta de atividade de Investigação explora o desperdício das águas e a qualidade da água que chega e que sai das residências. Logo, entende-se que este TDC está posto no capítulo como uma situação-problema, o ponto de partida para a investigação.

De maneira geral, o uso dos TDCs no Livro B, possui objetivos claros, os quais, possibilitam ao estudante desenvolver habilidades cognitivas como argumentar e criar hipóteses para resolução de problemas.

O Livro $C$, dentre os demais, é o que apresentou um direcionamento mais evidente do uso do TDC. Esta obra pode ser classificada como inovadora, pois busca tratar de temas atuais, desenvolvendo habilidades e utilizando linguagem científica ao longo do capítulo, para responder as questões propostas apresentadas no início do capítulo. Aproximamos essa metodologia da proposta de Estudo de Caso. No início de cada capítulo, a abertura é feita com um texto jornalístico relacionado a um tema do qual são extraídas as questões de discussão. No final do capítulo, as questões são retomadas, fazendo uma discussão com base nos conceitos estudados.

O Estudo de Caso ou Estudos de Caso compreendem três etapas: 1) identificar e definir o problema, acessar, avaliar; 2) usar informações necessárias à solução do problema; 3) apresentar a solução do problema.

Sá e Queiroz (2010) apontam que "TDCs podem ser inspiração para desenvolver estudos de caso, mas eles próprios não o são" (SÁ; QUEIROZ, 2010, p. 20). O que ocorre no Livro $C$ é que o TDC é apresentado como forma de introdução à discussão do conceito químico relacionado com questões do contexto social e a problematização é iniciada, permitimo-nos fazer esta aproximação, pois "O método de estudo de caso é comumente empregado para introduzir conteúdos" (SÁ; QUEIROZ, 2010, p. 31).

As mesmas autoras ainda alertam quanto à qualidade TDC para o estudo de caso, pois "para criar um "bom" estudo de caso utilizando TDC, o texto deve tratar de questões atuais, abordar assuntos passíveis de questionamentos a respeito de questões sociais, econômicas, ambientais e éticas, e ser relevante para o público-alvo" (SÁ; QUEIROZ, 2010, p. 20).

A autora do Livro $C$ não utiliza personagens, mas o TDC se encaixa em três das quatro etapas de elaboração de estudo de caso, de acordo com Sá e Queiroz (2010, p. 23), as quais são denominadas como: 
1- Escolha do assunto principal a ser destacado no caso - ele deve ser relevante dentro do contexto da disciplina a ser ministrada e, de preferência, também deve estar relacionada com questões atuais e/ou controvérsias;

2- Elaboração de uma lista dos possíveis conceitos/habilidades/atitudes que se pretende abordar por meio da aplicação do caso - para que em sua construção sejam inseridas questões e situações que possam conduzir ao desenvolvimento de tais aspectos;

3- Elaboração de uma lista dos possíveis personagens do caso - deverão apresentar características pertinentes à situação geral neles apresentada;

4- Elaboração de uma série de questões para discussão em sala de aula - essas questões auxiliarão os alunos a reconhecerem aspectos importantes, passíveis de serem discutidos a partir da solução do caso.

Considerando que o Estudo de Caso requer do estudante argumentação para resolver a questão proposta, esta deve ser reflexiva e este subsídio é fomentado ao longo do desenvolvimento do capítulo, então se espera que ao final do capítulo o estudante seja capaz de utilizar os conhecimentos adquiridos para responder às questões iniciais da problematização, assim como expressa na proposta dos autores para o Livro C. Desta forma, este livro possibilita o desenvolvimento de habilidades cognitivas importantes para a solução de problemas.

O Livro D apresenta o conteúdo de maneira sistêmica e linear. Os conceitos químicos são atrelados à exemplificação do cotidiano. Os TDCs, nesta obra, possuem várias funções dentro da proposta para a sua utilização. Contudo, a que mais se repete é onde o TDC é apresentado na seção Ciência, Tecnologia e Sociedade, sempre no final do capítulo. A proposta dos autores deste livro é muito simples, um texto da mídia com temas relacionados à perspectiva CTS.

$\mathrm{Na}$ tentativa de contextualizar o conteúdo de química são apresentados exemplos de utilização do conhecimento científico no cotidiano. Porém, isto não se caracteriza como contextualização, pois abordagens CTS "[...] tratam das inter-relações entre explicação científica, planejamento tecnológico e solução de problemas, e tomada de decisão sobre temas práticos de importância social" (SANTOS; MORTIMER, 2002, p. 112).

A exemplificação é um tipo de contextualização. Segundo Wartha e Alário (2005) apud Wartha, Silva e Bejarano (2013) "Os autores identificaram que, nos livros, a ideia de contextualização se restringe à exemplificação de fatos do dia a dia e à descrição científica de fatos e processos do cotidiano do aluno [...]" (WARTHA; SILVA; BEJARANO, 2013, p. 87). As questões de discussão propostas para cada seção, em geral, são meramente interpretativas e, em alguns casos, de aplicação dos conhecimentos aprendidos no capítulo. Por exemplo, no livro D, capítulo "O comportamento dos gases", o texto: "A caixa preta do 

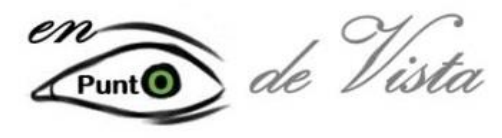

permafrost" localizado no final do capítulo, página 174, trata dos gases de efeito estufa causando degelo em regiões frias e no final do texto encontram-se algumas questões de interpretação do texto. O capítulo aborda os conceitos de cinética, pressão, volume e temperatura e as transformações gasosas. Neste caso, os autores não conseguiram estabelecer uma relação direta e evidente com os conceitos químicos apresentados; então os estudantes dificilmente utilizarão os conhecimentos científicos estudados no capítulo para responder as questões propostas. Dito de outro modo, não há um problema a ser solucionado, consequentemente não há necessidade de tomada de decisão nas atividades que seguem os TDCs, neste caso. Esta forma de apresentação do TDC no livro contrapõe-se aos pressupostos da abordagem CTS apresentada pelos autores como referência para a proposta didática do livro.

O Livro E apresentou diversas propostas para o uso do TDC. A situação mais presente é o TDC estar inserido no interior da questão das atividades. O TDC faz parte da problematização da questão, essas questões são, em sua maioria, de interpretação do texto, aplicação do conceito químico e reflexão de conexões entre conteúdos científicos e aspectos sociais e ambientais. Esta obra, dentre as demais, é a única que utiliza o TDC em questões a serem respondidas pelos estudantes.

Esta proposta é interessante do ponto de vista do estudo de texto, assim como pontua Azambuja e Souza (2011):

\begin{abstract}
Assim sendo, estudar um texto é trabalhar nele de modo analítico e crítico, desvendando-lhe sua estrutura, percebendo os recursos utilizados pelo autor para a transmissão da mensagem, descobrindo o objetivo do autor, antevendo hipóteses, testando-as confirmando-as ou refutando-as. Para que o Estudo de Texto se realize com plenitude, além do desenvolvimento das habilidades de compreensão, análise, síntese, julgamento, inferência etc., é necessário que haja, também, uma etapa final, em que os alunos exteriorizem, pela produção própria, algo que adquiriram com o Estudo de Texto (AZAMBUJA; SOUZA, 2011, p. 51).
\end{abstract}

Ao propor o TDC ou um recorte de TDC em uma questão, a fim de problematizá-la, o TDC é "bem aproveitado", pois para responder as questões é necessário que o estudante leia o texto com atenção, e de fato desenvolva as habilidades citadas por Azambuja e Souza (2011).

Em alguns momentos os autores do Livro $E$, apresentam o TDC como conexão com seu próprio discurso, quando pretendem realizar uma contextualização de um conceito químico, e isto ocorre, em geral, no início do capítulo.

Por fim, classificamos esta obra como tradicional, apesar de trazer os TDCs com uma abordagem diferenciada, como a problematização de questões, devido a sua natureza pouco 
organizada em relação a este recurso. Ao inserir TDCs em diversas posições ao longo do capítulo, não foi possível compreender a intenção dos autores ao incluírem este tipo de material.

Já o Livro F, apresenta pouco o recurso TDC, apenas dois TDCs em 3 volumes da obra, sendo que em um dos volumes não há nenhum TDC. No entanto, quando o apresenta, faz uso de modo a acompanhar a proposta problematizadora da própria concepção metodológica que a obra possui. Assim como os próprios autores classificam esta obra é considerada inovadora, pois busca contextualizar, problematizar os conceitos químicos e, desta forma, seu próprio discurso é contextualizado, utilizando poucos recursos como textos midiáticos. Os autores trazem o conhecimento químico apresentando propostas de experimentação investigativa, poemas (alguns casos), muitas imagens e ilustrações, entre outros. Quando utiliza o TDC, existe uma conexão direta entre o texto principal e o recorte, havendo uma ancoragem de ideias para a reflexão de um determinado assunto.

Os próprios autores, em uma carta aos professores no manual do professor presente na obra se autodenominam como inovador:

A característica marcante dele [do livro] está no caráter inovador. Fundamentados em princípios teórico-metodológicos, buscamos unir resultados de pesquisas em ensino de Química a uma proposta curricular que se enquadre às Diretrizes Curriculares Nacionais para o Ensino Médio (DCNEM) e ao que vem sendo discutido na Base Nacional Comum Curricular (BNCC). Tivemos a preocupação central de apresentar os conteúdos de Química, da forma mais clara possível, para os alunos, buscando justificar a origem conceitual. O nosso compromisso é com o aprendizado de conceitos e não com a memorização descontextualizada de termos químicos (SANTOS; MOL, 2016, p. 291).

Este tipo de material didático, por vezes, é pouco atrativo, em vista de sua proposta ser considerada complexa por alguns professores, no entanto, são as obras mais próximas a atender demandas das propostas curriculares dos documentos educacionais brasileiros, assim como as indicações de pesquisas na área de ensino de química.

Em suma, esta análise demonstrou que as inserções dos TDCs nos LDQs não são centralizadas em uma única possibilidade. Das seis coleções analisadas, temos seis propostas diferentes para o uso deste recurso: Contextualização, Investigação, Estudo de Caso, Exemplificação, Estudo do Texto e Problematização.

No entanto, refletimos que, estes TDCs ao serem inseridos nos LDQs não são reformulados, sendo assim, produtos da mídia, neste caso, apenas é transferido de contexto, sai do social (midiático) e se insere no contexto didático. Seu novo objetivo é o ser instrumento de ensino. Entendemos a necessidade de estar associado com uma 
metodologia ou proposta, na qual o texto seja "aproveitado" de maneira coerente, vinculado ao ensino, para que não seja apenas uma informação a mais.

Dentre os LDQs analisados, três deles apresentaram metodologias que possibilitam o desenvolvimento de habilidades de leitura crítica. Os demais trazem os TDCs com propostas interessantes do ponto de vista que, apesar de não inovarem, possuem mecanismos que possibilitam o aproveitamento deste recurso. Porém, em cada uma das formas propostas sempre dependerá da atitude que o professor em estabelecer e discutir a relação dos TDCs com aquilo que faz parte do conhecimento formal de química. É a motivação do professor e sua mediação que irá possibilitar uma leitura crítica dos alunos frente a qualquer um dos textos presentes no LD, pois mesmo que os autores dos livros insiram TDCs de uma maneira inovadora, sem que haja a mediação do professor o objetivo de trazer a divulgação da ciência para sala de aula não pode ser alcançado.

Salientamos que, quantidade de TDCs não representou qualidade de propostas didáticas para o Ensino de Química. As obras que apresentaram maior quantidade em termos de textos provenientes da mídia, não trouxeram elementos que possibilitem a interação direta com o conteúdo químico. Acreditamos que estes autores podem ter inseridos estes textos como medida para alcançar os critérios estabelecidos pelo PNLD, que visa à constituição de obras com caráter atuais, buscando envolver os conceitos com o cotidiano do estudante.

É um hábito (comum pelo que percebemos) que os TDCs sejam incluídos à obra, depois que o texto didático esteja quase completo. Ao fazer a busca pelos textos utilizando sua fonte citada nos livros, observamos que, em grande parte, os links foram acessados na mesma data, portanto, podemos presumir que a inserção destes textos tenha sido feita sem um objetivo claro, que seja para além de incluir textos de assunto de domínio midiático, mas também preencher lacunas. Esta é uma situação que nos deparamos em outros dos LDQs analisados, porém, ao finalizarmos a pesquisa, foi possível encontrar um padrão e entender a intenção e a proposta metodológica dos TDCs nestes livros. Neste sentido, entendemos que não depende da necessidade ou não da inserção deste recurso, mas da intencionalidade pretendida.

Neste sentido, todo TDC inserido em livro didático deve estar relacionado ao texto didático, estabelecendo-se as conexões e relações entre um e outro, caso contrário, perdese o sentido de trazer este recurso para dentro do livro e para a sala de aula.

\section{CONSIDERAÇÕES FINAIS}

A Química e o Ensino de Química nos permitem fazer relações entre o contexto social e a sala de aula visto que na atualidade, cada vez mais, a população está interessada em 

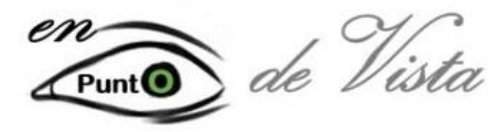

Ciência e Tecnologia, refletindo em uma Ciência eminentemente social, que busca resolver problemas da sociedade e proporcionar maior comodidade para a população. Sabemos que não se trata apenas deste objetivo, contudo, é de senso comum que os estudantes possuam esta visão, assim como grande parte do público não especialista.

Os TDCs como produto de divulgação da Ciência e Tecnologia, se tratados com as potencialidades vinculados à outras metodologias, recursos e conectados aos conceitos e conteúdos, podem alcançar, pelo menos parte, desses objetivos, ao serem inseridos em livros didáticos.

Esta análise retrata as diferentes propostas didáticas dos autores em relacionar a divulgação da ciência com os conceitos científicos por meio de TDCs, neste sentido, podemos concluir que é importante que o autor insira os textos dentro de uma abordagem metodológica inovadora e que estabeleça conexões do texto com o conteúdo científico.

Por fim, destacamos que este estudo tratou de uma análise específica de TDCs presentes em LDQs e que não foi nossa intenção classificar as obras como "boas" ou "ruins", mas apontar elementos para discussão da inserção de TDCs nos livros e, consequentemente, nas aulas de Química. Neste sentido, outras análises podem e devem ser realizadas em livros didáticos de modo a investigar outros temas, abordagens e recursos que são propostos por autores de livros didáticos. Tudo isso servirá de subsídio aos professores para definição e escolha dos livros didáticos que farão para das aulas de química na escola.

\section{Agradecimentos}

Ao financiamento da pesquisa por meio do CNPq e Fundação Araucária.

Ao Núcleo de Ensino em Ciências de Toledo (NECTO) pelo apoio logístico para realização da pesquisa.

Aos professores da rede estadual de ensino que forneceram os exemplares de livros didáticos para análise.

\section{REFERÊNCIAS}

ANGERAMI, E. L. S.; ALMEIDA, M. C. P. de. Divulgação do conhecimento científico produzido na enfermagem. Rev. Esc. Enf. USP, São Paulo, 16(2): p. 211-223, 1982. Disponível em: http://www.scielo.br/pdf/reeusp/v16n2/0080-6234-reeusp-16-2-211.pdf. Acesso em: 29 de nov. 2019.

AZAMBUJA, J. Q.; SOUZA, M. L. R. O Estudo de Texto como Técnica de Ensino. In: VEIGA, I. A. (Org.). Técnicas de ensino: Por que não? 21. ed. Campinas, SP: Papirus, p. 49-66. 2011.

BERNSTEIN, B. A estruturação do discurso pedagógico: classe, códigos e controle. Petrópolis: Vozes. 1996. BRASIL. Ministério da Educação. Secretaria de Educação Básica. PNLD 2018: química - Guia de livros didáticos ensino médio. Brasília, DF: Ministério da Educação, Secretária de Educação Básica, 2017.

CAPECCHI, M. C. V. M. Problematização no ensino de Ciências. In: CARVALHO, A. M. P. (org). Ensino de Ciências por Investigação: Condições para implementação em sala de aula. São Paulo: Ed. Cengage Learning, p. 21-39. 2014. 

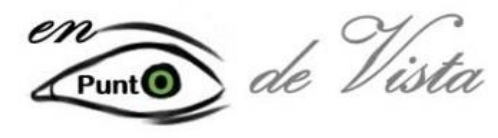

CHOPPIN, A. História dos livros e das edições didáticas: sobre o estado da arte. Educação e Pesquisa - FEUSP, São Paulo, v. 30, n. 3, p. 549-566, 2004.

CISCATO, C. A. M; PEREIRA, L. F; CHEMELLO, E.; PROTI, P.B. Química - Ciscato, Pereira, Chemello e Proti: Ensino Médio. São Paulo: Editora Moderna. 2016.

CUNHA, M. B. A percepção de Ciência e Tecnologia dos estudantes de Ensino Médio e a Divulgação Científica. Tese de Doutorado. Faculdade de Educação, Universidade de São Paulo, 2009.

CUNHA, M. B. Divulgação Científica: Diálogos com o Ensino de Ciências. Curitiba: Appris, 2019.

CUNHA. M. V. História da Educação e Retórica: Ethos e Pathos como meios de prova. In: SILVA, M.;

VALDEMARIN, V. T. Pesquisa em Educação: Métodos e Modos de Fazer. São Paulo: Ed. Cultura Acadêmica, p. 11-46. 2010.

LIMA. G. S.; GIORDAN, M. A Divulgação Científica Em Sala De Aula: Aportes do Planejamento de Ensino entre Professores de Ciências. In: GIORDAN, M., CUNHA, M. B. (Org.). Divulgação científica na sala de aula: perspectivas e possibilidades. Ijuí: Ed. Unijuí, p. 285-306. 2015.

LISBOA, J. C. F. Obra coletiva. Ser Protagonista: Química. São Paulo: Editora SM. 2016.

MACHADO, A. H.; MORTIMER, E. F. Química: Ensino Médio. São Paulo: Editora Scipione. 2016.

MALDANER, O. A.; ZANON, L. B. Situação de estudo: uma organização do ensino que extrapola a formação disciplinar em ciências. In: MORAES, R.; MANCUSO, R. (Org.). Educação em ciências: produção de currículos e formação de professores. Ijuí: Editora Unijuí, p. 43-64. 2004.

MARANDINO, M. Transposição ou recontextualização? Sobre a produção de saberes na educação em museus de ciências. Revista Brasileira de Educação, São Paulo, n. 26, p. 95-108, 2004.

MARTINS, I.; DAMASCENO, A. R. Uma análise das incorporações de textos de divulgação científica em livros didáticos de ciências. In: VIII Encontro de Pesquisa em Ensino de Física - SP, São Paulo: Atas do VIII Encontro de Pesquisa em Ensino de Física. São Paulo: SBF. 2002. Disponível em <http://www.sbf1.sbfisica.org.br/eventos/epef/viii/PDFs/CO18_1.pdf>. Acesso em: 30 out. 2019.

MOL, G. S. O Livro Didático Como Possibilidade de Mediação de Inovações na Sala de Aula. In. Ensino de Química Visões e Reflexões. 2. ed. Ijuí: Ed. Uniiuí, p. 27-51. 2012.

MOTTA-ROTH, D. Sistemas de gêneros e recontextualização na mídia eletrônica. Revista Gragoatá, n. 28, p. 153-174. 2010.

NOVAIS, V.L.D. de; TISSONI, M. Vivá: Química - Ensino Médio. Curitiba: Editora Positivo. 2016.

REIS, M. Química: Ensino Médio. São Paulo: Editora Ática. 2016.

SÁ, L. P; QUEIROZ, S. L. Estudo de casos no ensino de química. Editora Átomo. Campinas, 2010.

SANTOS, W. L. P; MORTIMER, E.F. Uma análise de pressupostos teóricos da abordagem C-T-S (Ciência -

Tecnologia - Sociedade) no contexto da educação brasileira. Rev. Ensaio. Belo Horizonte. v.02, n.02, p.110-132, 2000.

SANTOS, W.; MÓL, G. Obra Coletiva. Química Cidadã: Ensino Médio. São Paulo. Editora AJS. 2016.

WARTHA, E. J.; SILVA, E. L. da.; BEJARANO, N. R. R. Cotidiano e Contextualização no Ensino de Química. Revista Química Nova. V. 35, n. 2, p. 84-91,2013.

ZAMBONI, L. M. S. Cientistas, jornalistas e a divulgação científica: subjetividade heterogeneidade no discurso de divulgação científica. Campinas: Autores Associados. 2001. 

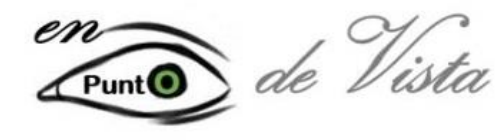

A Divulgação Científica (DC) possui um papel essencial no que se refere à difusão da ciência, por meio de revistas de divulgação da ciência, jornais, internet, entre outros. Os autores de Livros Didáticos de Química (LDQs) têm se apropriado de Textos de Divulgação Científica (TDCs) para complementar sua obra, trazendo assuntos com temáticas contemporâneas. Deste modo, investigamos qual a posição metodológica dos TDCs encontrados nos LDQs aprovados pelo Programa Nacional do Livro Didático (PNLD 2018). Buscamos todos os textos complementares nos LDQs e os caracterizamos como TDCs de acordo com os critérios de Zamboni (2001). Aproximamos a proposta de uso dos TDCs pelos autores a metodologias de ensino como: Problematização, Estudo de Caso, Investigação, Contextualização e Estudo do Texto. Neste estudo apontamos os principais aspectos da utilização destes textos nos livros didáticos e consequentemente na sala de aula.

\section{RESUMEN}

La Divulgación Científica (DC) desempeña papel esencial en la divulgación de la ciencia a través de periódicos de divulgación científica, Internet, entre otros. Los autores de los Libros de Texto de Química (LTQ) se han apropiado de los textos de divulgación científica (TDC) para complementar su trabajo, trayendo temas contemporáneos. Investigamos la posición metodológica de los TDCs que se encuentran en los LTQ aprobados por el Programa Nacional de Livros de Texto (Brasil, PNLD 2018). Se realizaron búsquedas en todos los textos complementarios en los LTQ y los caracterizamos como TDC según los criterios de Zamboni (2001). Las metodologías de enseñanza presentes em los libros donde se encuentran los textos de divulgación científica son: Problematización, Estudio de Caso, Investigación, Contextualización y Estudio de Texto. En este estudio señalamos los principales aspectos del uso de estos textos en los libros de texto y, en consecuencia, en el aula. 